\section{Independent medical evaluations}

Ebrahim and colleagues, ${ }^{1}$ identify important ethical and legal concerns relating to independent medical evaluations (IMEs). The authors ${ }^{1}$ question whether the patient (examinee) has the right to receive a copy of the independent medical evaluation report. However, the current clinical standard in Canada, which is reinforced by legislation, is that patients do have a right to their health information. For example, the Personal Information Protection and Electronic Documents Act and the corresponding provincial acts guarantee that the patient has access to health information and the right to ask for corrections to be made where necessary.

Also, the assumption is that the patient has given consent for the collection of the health information. One might want to consider whether giving free consent is possible for patients, when the consequence of withholding consent is the loss of disability benefits.

The authors ${ }^{1}$ also emphasize that physicians undertaking an IME are not in a treatment relationship with the patient. Therefore, it becomes problematic when these physicians make treatment recommendations, because this runs contrary to medical practice regulatory requirements.

\section{Alan B. Eppel MD}

Physician, McMaster University, Hamilton, Ont.

\section{Reference}

1. Ebrahim S, Sava H, Kunz R, et al. Ethics and legalities associated with independent medical evaluations. CMAJ 2014;186:248-9.

CMAJ 2014. DOI:10.1503/cmaj.114-0058

I have conducted several thousand independent medical examinations, and from time to time, as pointed out by Ebrahim ${ }^{1}$ in his $C M A J$ commentary, the examinee has a serious medical problem. In my view, our obligation to the individual demands that we take some type of definitive action when the litigant being examined has a serious medical problem. On one occasion, I certified and sent an examinee directly to hospital by ambulance, because I believed the examinee was actively suicidal.

In less serious situations, on four or five occasions, I have called the legal counsel who engaged me and expressed my concern about the examinee. I have sought permission from legal counsel to call the examinee's family physician or treating specialist to express my concern. On all occasions, legal counsel was happy to have me do so.

To ensure that examinees understand the purpose of the assessment, I always have them sign a full consent form. The form outlines the purpose of the examination, points out that there is no doctor-patient relationship and indicates that I will not be giving them any advice regarding treatment.

\section{Derryck H. Smith MD}

Clinical Professor Emeritus, Department of Psychiatry University of British Columbia, Vancouver, BC

\section{Reference}

1. Ebrahim S, Sava H, Kunz R, et al. Ethics and legalities associated with independent medical evaluations. CMAJ 2014;186: 248-9.

CMAJ 2014. DOI:10.1503/cmaj.114-0059

\section{Persistent postoperative nonanginal pain after cardiac surgery}

As the two principal research investigators, we are pleased that our large, longterm, multicentre study on persistent postcardiac surgery pain was published in CMAJ. ${ }^{1}$ However, we strongly take issue with the Editor's comment in the April 15 print synopsis version regarding the data in the full-text article. We point out the editor's misunderstanding referring to persistent preoperative nonanginal pain: "If the measurement scales were comparable, this suggests a great improvement from 6 months after surgery onward rather than a persisting problem." We think that this merits a correction in CMAJ. Pain measurement before surgery related to an already existing persistent nonanginal pain from common health problems such as arthritis, headache or backache, while this study measured surgery-related pain that remained for about $10 \%$ of patients at two years later. As mentioned in our original manuscript, persistent postoperative pain was defined as pain that: first appeared after surgery, was not related to pain felt before surgery (e.g., anginal pain) or to other causes (e.g., infection, arthritis) and was present for at least three months.

Readers must not lose sight of the very important study findings supporting persistent pain as a potential consequence of this very common cardiac surgery. Patients with higher ratings for acute pain and related interference in daily functioning in the first week after surgery were more likely to report persistent postoperative pain at 2 years later. Cardiac surgeries rank among the most frequently performed interventions worldwide, ${ }^{2}$ and prevalence rates of long-term postoperative pain after these surgeries is substantial. Both clinicians and patients need to be informed of this potential consequence.

Unrelieved acute severe pain in the immediate postoperative period has been documented for decades and again in our study. The severity of persistent postoperative pain should be amenable to change. Future well-designed, carefully controlled studies are needed to determine whether persistent postoperative pain can be minimized or prevented.

\section{Manon Choinière PhD, Judy Watt- Watson PhD \\ Centre de recherche de Centre hospitalier de l'Université de Montréal (Choinière); Département d'anesthésiologie (Choinière), Université de Montréal; Montreal Heart Institute Research Centre (Choinière), Montréal, Que.; Faculty of Nursing (Watt-Watson), University of Toronto; Toronto, Ont.}

\section{References}

1. Choinière $\mathrm{M}$, Watt-Watson $\mathrm{J}$, Victor $\mathrm{JC}$, et al Prevalence of and risk factors for persistent postoperative nonanginal pain after cardiac surgery: a 2-year prospective multicentre study. CMAJ 2014; 186:E213-23.

2. Roger VL, Go AS, Lloyd-Jones DM, et al. Heart disease and stroke statistics — 2012 update: a report from the American Heart Association. Circulation 2012;125:e2220.

CMAJ 2014. DOI:10.1503/cmaj.114-0057 